\title{
Premature terminator analysis sheds light on a hidden world of bacterial transcriptional attenuation
}

\author{
Magali Naville, Daniel Gautheret ${ }^{*}$
}

\begin{abstract}
Background: Bacterial transcription attenuation occurs through a variety of cis-regulatory elements that control gene expression in response to a wide range of signals. The signal-sensing structures in attenuators are so diverse and rapidly evolving that only a small fraction have been properly annotated and characterized to date. Here we apply a broad-spectrum detection tool in order to achieve a more complete view of the transcriptional attenuation complement of key bacterial species.

Results: Our protocol seeks gene families with an unusual frequency of $5^{\prime}$ terminators found across multiple species. Many of the detected attenuators are part of annotated elements, such as riboswitches or T-boxes, which often operate through transcriptional attenuation. However, a significant fraction of candidates were not previously characterized in spite of their unmistakable footprint. We further characterized some of these new elements using sequence and secondary structure analysis. We also present elements that may control the expression of several non-homologous genes, suggesting co-transcription and response to common signals. An important class of such elements, which we called mobile attenuators, is provided by $3^{\prime}$ terminators of insertion sequences or prophages that may be exapted as $5^{\prime}$ regulators when inserted directly upstream of a cellular gene.

Conclusions: We show here that attenuators involve a complex landscape of signal-detection structures spanning the entire bacterial domain. We discuss possible scenarios through which these diverse $5^{\prime}$ regulatory structures may arise or evolve.
\end{abstract}

\section{Background}

Transcription of protein-coding genes does not always lead to the production of full length mRNAs. In both eukaryotes and bacteria, transcriptome analysis is revealing high levels of short transcripts that result from either unsuccessful initiation events or premature termination [1-4]. In eukaryotes, the functions of such events remain unelucidated, except for a few cases [5], and abortive transcription is still largely considered as transcriptional 'noise'. In Bacteria however, a form of abortive transcription known as transcription attenuation has emerged as an important regulatory strategy. The basic principle of transcriptional attenuation is the folding of the RNA transcript into either of two alternative structures, one of them corresponding to a Rho-independent terminator.

\footnotetext{
* Correspondence: daniel.gautheret@u-psud.fr

Université Paris-Sud, CNRS, UMR8621, Institut de Génétique et Microbiologie, Bâtiment 400, F-91405 Orsay Cedex, France
}

The expression/repression decision occurs through a sensing system located between the promoter and the first start codon of the operon, and depends on interactions modulated by a variety of signals. The type of signal detected is commonly used to classify attenuators into major families: riboswitches bind small metabolites [6-8], T-boxes bind tRNAs $[9,10]$, and other types of 5 ' leaders respond to protein factors [11-13] or temperature [14-16]. The triggering signals, by reflecting the global physiological state of the cell, enable a continuous monitoring of operon expression requirements.

A number of computational strategies have been proposed for attenuator prediction. The most general approaches consist of the identification of mutually exclusive RNA secondary structures $[17,18]$, with the limitation that they miss non-hairpin anti-terminators such as riboswitches whose anti-terminator corresponds to a much larger secondary structure. Other and more

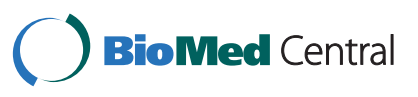

(c) 2010 Naville and Gautheret; licensee BioMed Central Ltd. This is an open access article distributed under the terms of the Creative Commons Attribution License (http://creativecommons.org/licenses/by/2.0), which permits unrestricted use, distribution, and reproduction in any medium, provided the original work is properly cited. 
specific studies have been devoted to the screening of particular classes of attenuators, such as riboswitches [19-21], T-boxes [9] or leader peptide systems [22]. These screening strategies use either covariance models $[19,20]$ or descriptors combining sequence and structure motifs [23], which are designed to detect conspicuous, class-specific signatures. Signatures can be, for instance, an RNA fold, a conserved sequence, or the presence of a short ORF [22]. Such screens based on sequence or structure recognition identify highly conserved members of a family and, eventually, closely related variants. For instance, five distinct riboswitch families have been described that all sense S-adenosyl methionine (SAM I [24-26], SAM II [27], SAM III [28], SAM IV [29] and SAM V [30]).

In bacterial species, up to $10 \%$ of operons may be regulated by transcription attenuation [17]. In agreement with this assessment, we showed in a previous study [31] that a mean of $1.6 \%$ of all bacterial genes could be subject to attenuation, with a maximum of $2.6 \%$ in Firmicutes. However, knowledge on transcriptional attenuation is unevenly distributed: almost none of the predicted attenuators in phyla such as Chlamydiae or Acidobacteria have associated functions, whereas $16 \%$ are already annotated in Firmicutes. As previous attenuator screens were mostly based on similarity searches, known families often present a marked homogeneity and lack many evolutionarily isolated instances. Moreover, they exclude entire classes of elements that are either too short or too variable to produce signatures strong enough for a similarity search.

To fully explore the variety of attenuation systems, we need strategies that do not rely initially on sequence or structure homology. We developed a protocol that first screens all potential Rho-independent terminators in the 5 ' region of genes in multiple bacterial genomes and, in a second stage, extracts significant elements using two types of procedures: a synteny-based procedure that seeks gene families with unusually frequent 5 ' terminators; and a non-syntenic procedure that seeks sequences conserved among multiple putative terminators. Synteny analysis alone was able to pick up every class of known attenuation system, which are generally the most widespread, while allowing the prediction of numerous new instances. A major benefit of this strategy lies in the evolutionary insight it provides on attenuator families, as we illustrate below for five families of particular interest found throughout the 302 species surveyed. We further characterized new attenuators, in particular in Escherichia coli and Bacillus subtilis, using sequencebased analysis. Our results demonstrate that attenuator characterization can be largely improved even in widely analyzed model species.

\section{Results and discussion}

5' terminators are less stable than $\mathbf{3}^{\prime}$ terminators and unevenly distributed among species

We combined two methods for Rho-independent terminator prediction using either position weight matrices [32] or descriptors [33] to detect potential terminators in the 5' and 3' UTRs in 302 bacterial genomes (see Materials and methods for details). As already documented [34], the overall usage of Rho-independent terminators fluctuates among species, with a maximum in Firmicutes (approximately 2,689 predictions in Bacillus cereus) and a minimum in Actinobacteria (30 predictions in Nocardioides sp.) or in certain atypical species such as the proteobacteria Ehrlichia ruminantium (8 predictions), an obligate intracellular pathogenic organism. Controls performed using randomized UTR sequences indicate a low false positive rate in both 5' and 3' UTRs (2.3\% and $2.5 \%$, respectively; see Materials and methods). Based on experimentally verified B. subtilis operons, we estimate that our protocol would retrieve about $88 \%$ of 3' terminators [35].

To identify putative attenuators, we applied additional filters to the set of $5^{\prime}$ terminators, based on orientation and distance relative to flanking genes. In our set of 302 bacterial genomes, this led to the identification of 15,930 putative attenuators, 1,004 of them overlapping sequences previously annotated as ORFs encoding short hypothetical proteins. In B. subtilis, this protocol detected 32 of 57 (56\%) known attenuation systems (riboswitches, T-boxes and other elements).

Terminators found in 5' UTR regions are thermodynamically less stable than 3' terminators (average folding free energy of $-16.5 \mathrm{kcal}$ versus $-20.2 \mathrm{kcal} / \mathrm{mol}, P<2 \mathrm{e}-$ 16) and their average stem length is slightly shorter (7.0 versus $7.6 \mathrm{bp}, P<2 \mathrm{e}-16)$. As seen above, this difference cannot be imputed to a higher false discovery rate in 5' UTR, although it is in agreement with expected properties of structures that must fold alternatively; all known 5 ' regulatory terminators allow an alternative readthrough, which is not the case for 3' terminators. Interestingly, 5' terminators do not seem to be evolutionarily more conserved in sequence than 3' terminators. Analyzing data from a recent screen for non-coding conserved elements in bacteria [36], we observed that $58 \%$ of 5 ' terminators, versus $66 \%$ of 3' terminators, overlap a conserved region. This suggests that 5 ' terminators are not associated with conserved sequences more often than canonical terminators.

\section{Synteny analysis reveals more than $\mathbf{5 0}$ gene families subject to frequent attenuation control}

We classified 5' terminators based on homology relationships between downstream genes, an operation that 
amounts to seeking syntenic attenuator/gene pairs. This method is related to that of Merino and Yanofsky [17], who sought over-represented families of orthologous genes flanking putative attenuators. These authors defined attenuators based on mutually exclusive stems, while we look for single terminator motifs. In principle our approach should be more sensitive to transcriptional attenuators as some achieve their alternative state through contacts with external factors and do not require stable alternative base pairing. On the other hand, Merino and Yanofsky were able to detect translational attenuators, which we do not detect here.

To identify protein families showing a greater propensity for regulation by transcriptional attenuation, we used the Hogenom database of gene families [37] and ranked families based on numbers of 5 ' terminators. In a first procedure, we scored gene families according to absolute numbers of predicted attenuators across all species without any consideration of gene family size, which favored large families of paralogs (Table S0 in Additional file 1). To avoid bias towards large paralog families, we used a second scoring procedure where gene families were ranked according to their frequencies and species distribution (Figure 1). The significance of attenuator enrichment was confirmed independently for each family. Scores, $P$-values and family information are shown in Table S1 in Additional file 1. Our syntenybased scoring eliminates over $90 \%$ of the false positives corresponding to terminators of independent small RNA genes. While 2.2\% (343 elements) of the total 15,930 predicted 5' terminators map to annotated small RNAs, this fraction is reduced to $0.16 \%$ ( 3 out of 1,845 ) when considering only attenuator candidates from the 65 high-ranking families. Therefore, although some terminators of independent RNA genes are included in our initial screen, most of them are dismissed when we consider high-scoring gene families. Finally, we analyzed sequence conservation to detect possible functional elements associated with attenuators. To this aim, we performed pairwise sequence comparison of the terminator regions, followed by hierarchical clustering. Attenuator elements harboring a sequence conserved in at least two species are listed in Table S2 in Additional file 1 for the first 30 attenuator families.

We assessed prior knowledge of attenuator regulation in each gene family through a systematic literature survey and comparison to the Rfam RNA family database [38] and to the RegulonDB database of $E$. coli transcriptional networks [39]. The high incidence of known terminator systems among high-ranking families in Figure 1 underscores the specificity of our detection method. Forty-two out of 65 high-ranking families (65\%) were already described as attenuator-regulated in at least one species, covering virtually all known classes of attenuator systems (Figure 1). This proportion reaches $100 \%$ for the first 20 families. Within known attenuator families, however, a large fraction of elements were not described previously: $67 \%$ of elements are unannotated in the top 30 families. Furthermore, several major families of attenuators are essentially uncharacterized: 27 out of 65 are completely uncharacterized or are less than $1 \%$ characterized. In the following sections we describe five previously uncharacterized attenuator families, selected either because they are particularly widespread or functionally interesting or because they display intriguing phylogenetic patterns.

\section{The rimP-leader: the most ubiquitous transcription}

\section{attenuator}

The rimP gene ranks first in our list of genes most often regulated by attenuation (Figure 1 ). $\operatorname{rim} P$, previously known as $y h b C$ in $E$. coli and $y l x S$ in B. subtilis, encodes a protein recently shown to be involved in $30 \mathrm{~S}$ ribosomal subunit maturation [40]. It is the first gene of an operon encompassing the nus $A$ and inf $B$ genes, which are present in almost all bacteria. While infB encodes the translation initiation factor IF-2, the NusA protein is characterized as a transcriptional pausing, readthrough, termination and anti-termination factor, and is shown to participate in the Rho-dependent anti-termination complex [41].

Analysis of predicted attenuators in $\operatorname{rimP}-n u s A-i n f B$ operons (Figure $2 \mathrm{~b}$ ) revealed the presence of a short and highly conserved motif corresponding to the terminator, the 'rimP-leader', but gave no evidence of larger conserved elements characteristic of riboswitches, T-boxes or ribosomal protein-dependent attenuators. The terminator stem contains an unusual highly conserved GGGC (...) gCCC motif. We were unable to detect such a conserved motif in any other 5' or 3' terminator, suggesting this sequence signature is specific to the rimPleader. We could find, however, the same motif along with the downstream U-stretch in many 5' UTRs of rimP-nusA-infB operons where no terminator structure was detected (Supplementary data 1 in Additional file 1 ). These additional motifs were missed because the potential hairpin was too short for detection with our programs, consistent with our previous observation that regulatory terminators are less stable than regular terminators. The distance separating the terminator from the gene start varies between 4 and 130 nucleotides, and may consequently encompass the ribosome-binding site (RBS). In several Gammaproteobacteria (listed in Supplementary data 1 in Additional file 1), the rimP-leader appears more complex, with a second terminator found in tandem and upstream of the former (Figure 2a), and presenting a clear potential anti-terminator structure. Interestingly, this terminator presents a $\operatorname{CCCg}(\ldots)$ CGGG motif, inverse to the downstream motif. 


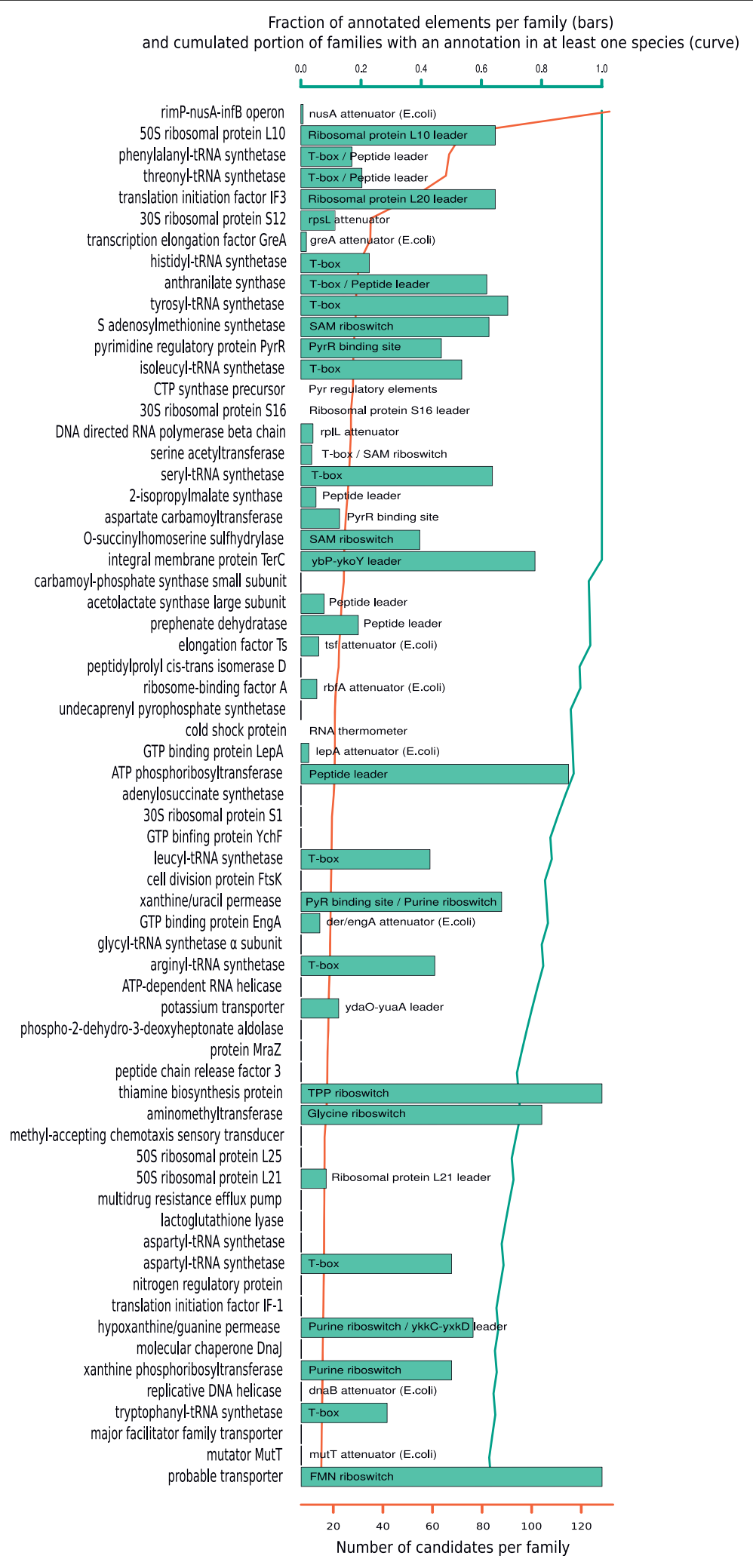

Figure 1 Sixty-five families of genes most frequently controlled by attenuation. For each gene family described on the left, the histogram bar shows the fraction of candidates already described in the Rfam database or in the literature. The green curve corresponds to the cumulated portion of families with at least one described candidate, from the first family to the 65th. The red curve indicates the absolute number of candidates in each family. 


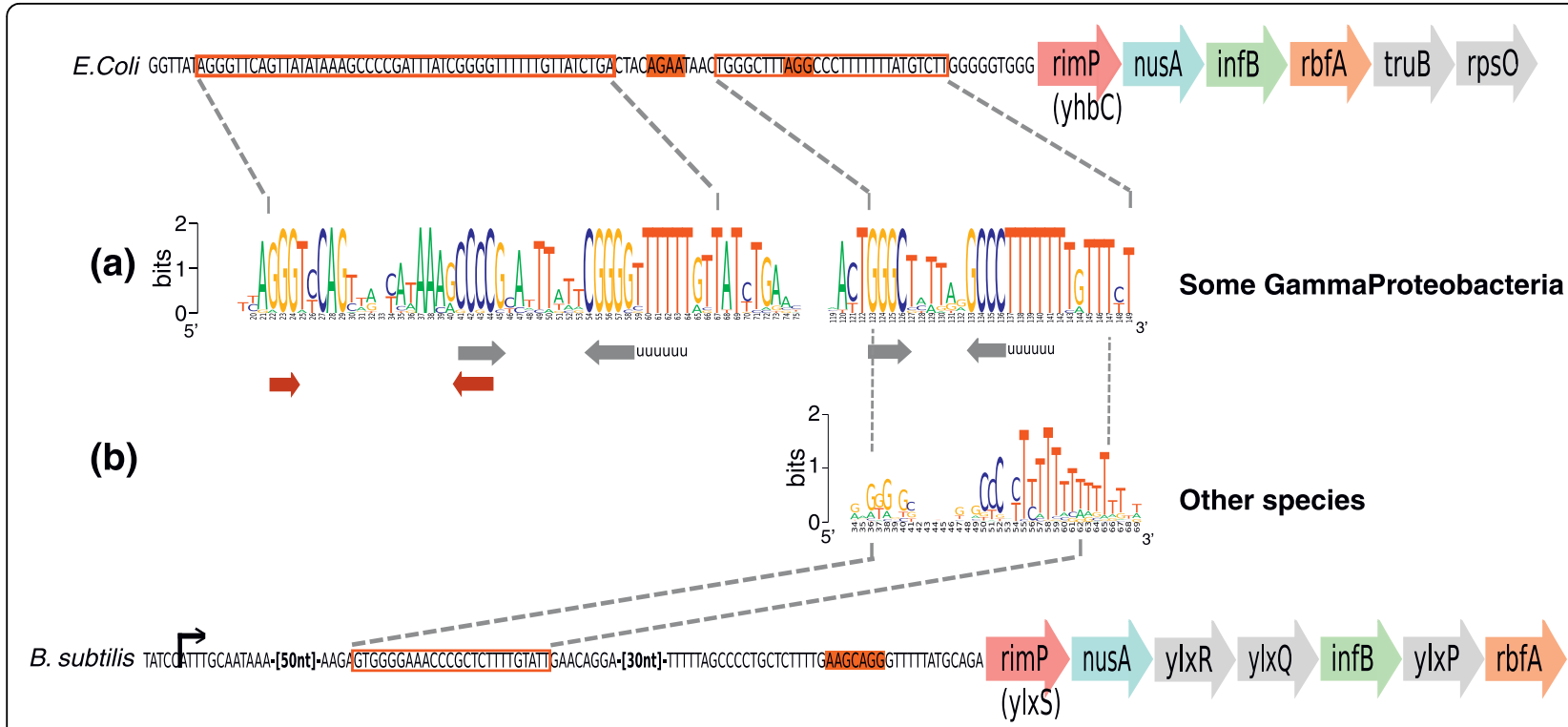

Figure 2 The rimP-leader. Highlighted boxes indicate putative ribosome binding sites. (a) rimP-leader identified in several Gammaproteobacteria (listed in Supplementary data 1 in Additional file 1), composed of a putative termination/antitermination structure (shown by thick arrows under the sequence) followed by the general rimP-leader motif described in the text. (b) rimP-leader found in the majority of species, including Firmicutes and Gammaproteobacteria. This leader sequence consists of a hairpin that is G-rich on its $5^{\prime}$ arm and C-rich on its $3^{\prime}$ arm, followed by the T-stretch characterizing Rho-independent terminators. The black arrow indicates the transcription start site recently detected by deep sequencing [46]. Sequence logos were produced using Weblogo [81].

High sequence conservation in the rimP-leader terminator stem and the absence of any visible antiterminator structure argue for regulation involving a termination or anti-termination protein that can specifically recognize a nucleic-acid motif $[12,13]$. If feedback control by RimP, now known to interact with rRNA [40], may be hypothesized, the best candidate for this direct interaction is probably the NusA protein, the expression of which was shown 25 years ago to repress expression of the operon $[42,43]$. NusA contains an amino-terminal domain that interacts with RNA polymerase, an S1 domain frequent in RNA-associated proteins, and two RNA-binding $\mathrm{K}$ homology $(\mathrm{KH})$ domains [44]. It was already shown to be involved in the attenuation of the Trp, His and S10 operons [45] by interacting with the upstream arm of the terminator hairpin, but the RNA motif we describe here was not observed in these instances.

While this manuscript was under review, a deep sequencing study of 5' regulators in B. subtilis [46] observed that transcripts encoding certain core transcription elongation subunits, including $y l x S$ (that is, $\operatorname{rim} P$ ), appear to contain a long 5 ' leader region. The authors suggested these regions may contain elements regulating the associated genes. The 180-nucleotide leader they observed by deep sequencing in $B$. subtilis rimP transcripts indeed covers the attenuator we predict for this gene (Figure 2).

\section{The rpsL-leader: a multiform ribosomal protein leader}

The rpsL gene also appears at the top of the list of genes frequently regulated by transcriptional attenuation (Figure 1). Like rimP, it belongs to an operon of largely conserved genes, rpsL and rpsG, encoding the ribosomal proteins $S 12$ and S7 respectively, and fusA and tufA, encoding the elongation factors EF-G and EF-Tu, respectively. Sequence-based clustering allowed us to identify variants among the different 'rpsL-leaders' (Table S2 in Additional file 1). We derived consensus structures for several of these elements and were able to find potential alternative antiterminator structures in each case (Figure 3).

The translation of rpsL and rps $G$ was already shown to be controlled by S7, the product of rpsG, in E. coli [47], and Merino and Yanofsky [17] predicted putative transcription attenuators upstream of $r p s L$ in 24 species. However, their results scantly overlap our own predictions: we have only four common candidates, while we scanned 22 of their 24 species. The occurrences we missed with our protocol involved non-canonical terminators (with a long, GC-poor and/or bulged hairpin), or terminators that were too far from the ATG to meet our distance filter (8 of 18 cases).

The persistence of an attenuator element upstream of rpsL in widely divergent species argues for a common origin. However, we found no globally conserved feature, neither in sequence nor in structure, associated 


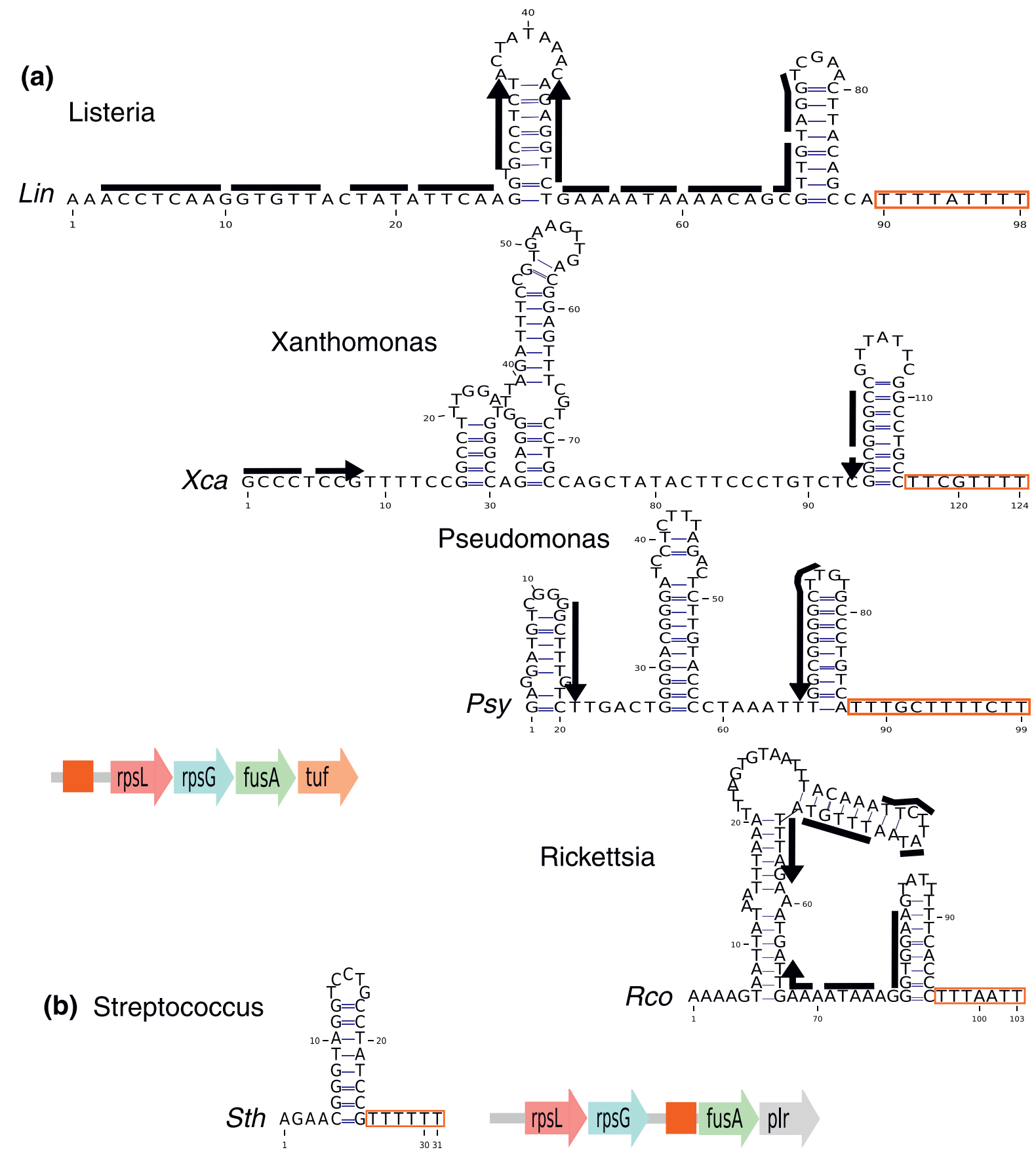

Figure 3 The rpsL-leader. Representative structures are shown for reference species, each corresponding to the consensus terminal structure of elements found in closely related species. Boxes indicate terminator T-stretches. Black arrows indicate putative anti-terminator structures. (a) Elements found upstream of the rpsL gene in Listeria, Xanthomonas, Pseudomonas and Rickettsia genera. (b) rpsL-leader found upstream of the gene fusA in streptococci.

with this attenuator. This probably explains why no common structure has been proposed for the rpsLleader previously. In the Streptococcus genus, we found no attenuator upstream of rpsL, contrary to Merino's analysis, which found one (this terminator is too far from the ATG codon (189 nucleotides) to satisfy our distance filter). However, we found a candidate further downstream between rpsG and fusA in streptococci (Figure $3 \mathrm{~b}$ ). It is possible that two similar elements are present in this operon, since Meyer et al. [48] found two similar RNA structures upstream of rpsL and fusA in the Proteobacteria Candidatus Pelagibacter ubique. This 
would be consistent with co-regulation of the two genes. The element identified in [48], however, does not meet our terminator criteria and does not present any common sequence feature with any of our predicted attenuators.

Is the structure and sequence diversity in rpsL-leaders compatible with an interaction with the same S7 protein partner in all species? The highly flexible RNA binding portion of S7 [49] could tolerate some variation in RNA targets or, alternatively, the leader may bind different protein partners. In the current view of ribosomal protein leaders, each leader family displays a characteristic motif that mimics corresponding binding sites in ribosomal RNA. This view may be too restrictive and the example of rpsL suggests that the modalities of interaction may differ across distant phyla.

\section{$A B C$-leaders: conferring specificity to regulatory elements}

ATP-binding cassette $(\mathrm{ABC})$ transporters constitute one of the largest and most ancient protein families, with hundreds of paralogs transporting a wide variety of substrates across the plasmic membrane, including ions, amino acids, lipids and drugs [50,51]. In Bacteria, these multiproteic complexes are encoded by operons comprising genes for ATPase, permease and periplasmic components. A number of them were shown to be regulated by transcriptional factors [52], whereas very few are known to be subject to transcriptional attenuation [53]. ABC transporters do not appear in Figure 1, where scores are weighted for family size; however, this family presents the highest absolute number of genes regulated by attenuation (Table S0 in Additional file 1), with a total of 205 candidates in our study, and an enrichment $P$-value of $8.8 \mathrm{e}-05$. Further scrutiny of these candidates is important because of the great diversity of transporters and potential variability of regulatory elements controlling them. We found different sequence motifs associated with these 'ABC-leaders' (listed in Table S3 in Additional file 1).

Figure 4 shows five $\mathrm{ABC}$-leaders associated with transporters of either known (Figure $4 \mathrm{a}-\mathrm{d}$ ) or unknown (Figure 4e) substrates. Each is able to form an antiterminator structure and the conserved sequence/structure motif (see alignments in Supplementary data 2 in Additional file 1) suggests that it responds to a unique substrate. The candidate shown in Figure $4 \mathrm{c}$ is a probable T-box, but the other candidates do not resemble any known cis-regulator. Their regulatory mechanisms thus remain to be determined. The size of the conserved structure is sufficient to form an aptamer that could directly detect a substrate, thus defining new classes of riboswitches; however, we cannot exclude an indirect regulation involving a protein factor. Indeed, a number a RNA-binding proteins target palindromic RNA [12,13] that may also act as a terminator hairpin.

The analysis of such a multiple paralog family raises interesting evolutionary questions on the origin of associated attenuators, that is, whether they all derive from an ancient attenuator that would have regulated the ancestral $\mathrm{ABC}$ transporter, or if certain genes of this family tend to 'attract' attenuators for their regulation. The relatively low proportion of attenuated ABC transporter genes and the ability of attenuators to 'hop' from one gene to another (see below) argue for the second hypothesis.

\section{Regulators of the hisS genes: switching between sensing systems}

Syntenic attenuation systems do not necessarily use the same sensing system. There are well known examples of switches from a T-box or a riboswitch in certain species (for example, Firmicutes) to a leader peptide in others (for example, Proteobacteria) [9,10]. Our protocol, which does not require a conserved RNA sequence or structure, is well suited to detect such exchanges, and at least five are present in our list of frequently attenuated genes (Figure 1).

A particularly striking case of switch between sensing systems is provided by the his $S$ gene (Figure 5 ). In the Bacillus genus, his $S$, encoding the histidyl-tRNA synthetase, has been long known to be regulated by a T-box, like many other tRNA synthetases [9]. This gene, however, underwent two successive duplications: a recent one that appears specific to bacilli, and a more ancestral one that occurred before divergence of the Proteobacteria and Firmicutes. Interestingly, all three paralogs now found in bacilli are predicted to be regulated by a different type of attenuator, as shown in Figure 5. In addition to the known hisS T-box, we found novel attenuators upstream of his $S^{*}$ (the Bacillus hisS paralog) and his $Z$, encoding an ATP phosphoribosyltransferase regulatory subunit.

We performed a sequence-based clustering of the 5' UTR regions in the his $S$ family to identify sets of related motifs (Figure 5). The 5' UTRs of his $Z$ and of his $S^{*}$ have highly similar sequences that include short ORFs encompassing a stretch of histidine codons. This strongly argues for the presence of a histidine leader peptide regulating both genes. To our knowledge, no leader peptide system had been shown to exist outside of Proteobacteria [22] and Actinobacteria [54], if we exclude the atypical erm $C$ leader [55] that controls translation and has no amino acid specificity but senses a global slowdown in translation. This result thus strengthens the evolutionary relevance of leader peptide systems and expands the range of RNA-based regulation in Gram-positive bacteria.

Leader peptides may have spread to Firmicutes by horizontal transfer. However, we may also hypothesize that short reading frames may have emerged repeatedly from random sequences, especially in the favorable cellular environment of species such as those in the 


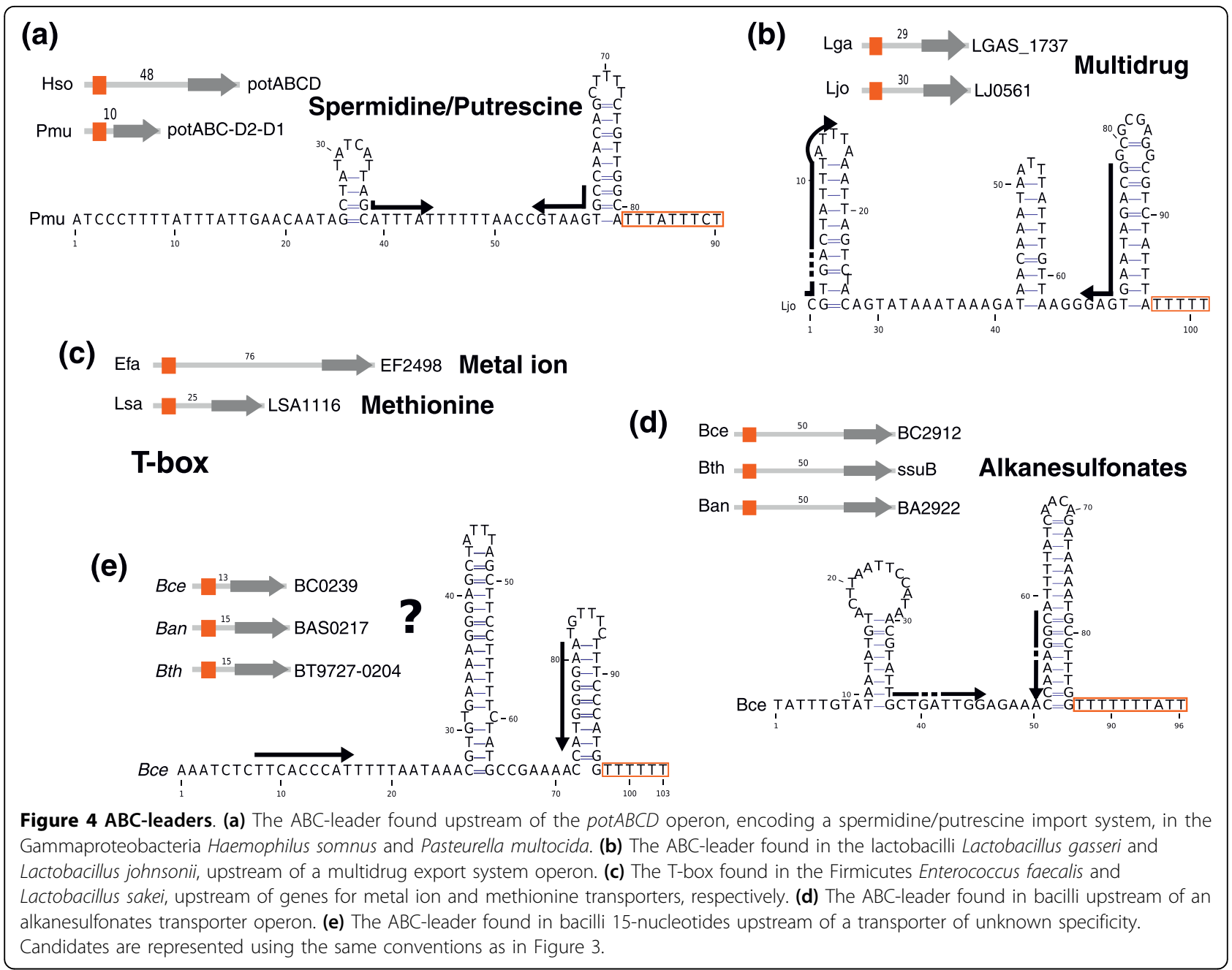

Firmicutes phylum. In support of convergent evolution, no similarity in the non-coding or leader peptide sequence is observed between the Firmicutes and Proteobacteria. That the two hisS gene duplications are observed only in certain Firmicutes species suggests a recent event: a gene resulting from the first duplication may have evolved or captured an attenuation system (for example, from a Gram-negative bacteria) before undergoing a second duplication.

Sequence analysis of his S attenuators also reveals a T-box element in Lactobacillales (Figure 5a). Furthermore, we observed one possible horizontal transfer of attenuator elements from Firmicutes to Gammaproteobacteria: an unknown proteobacterial attenuator, which corresponds to a sequence encompassing a putative short ORF, clearly resembles Firmicute T-boxes (Figure $5 \mathrm{c}$, red box). This illustrates the remarkable lability of attenuator elements, which can be acquired from other species and subsequently evolve to fit the preferred regulatory mechanisms of their new host.

\section{The related greA- and rnk-leaders}

The greA/rnk gene family ranks seventh in our list of genes frequently regulated by attenuation. Although the propensity of greA/rnk genes for transcriptional attenuation was detected previously [17], experimental evidence for an E. coli greA attenuator is recent [4]. The gene family includes two major paralogs, greA, which encodes a transcription elongation factor, and $r n k$, which encodes a regulator of nucleoside diphosphate kinase. We found attenuators upstream of these genes in species ranging from Proteobacteria to bacilli and Clostridia. In several species, we identified attenuators in both genes. Figure 6 shows the result of a sequence-based clustering of greA/rnk attenuators and secondary structure models for different sequence clusters. In each case, we were able to detect a clear antiterminator structure; however, no common feature could be detected between the greA- and $r n k$-leaders.

Very interestingly, the limited experimental evidence available on these two putative cis non-coding RNAs 


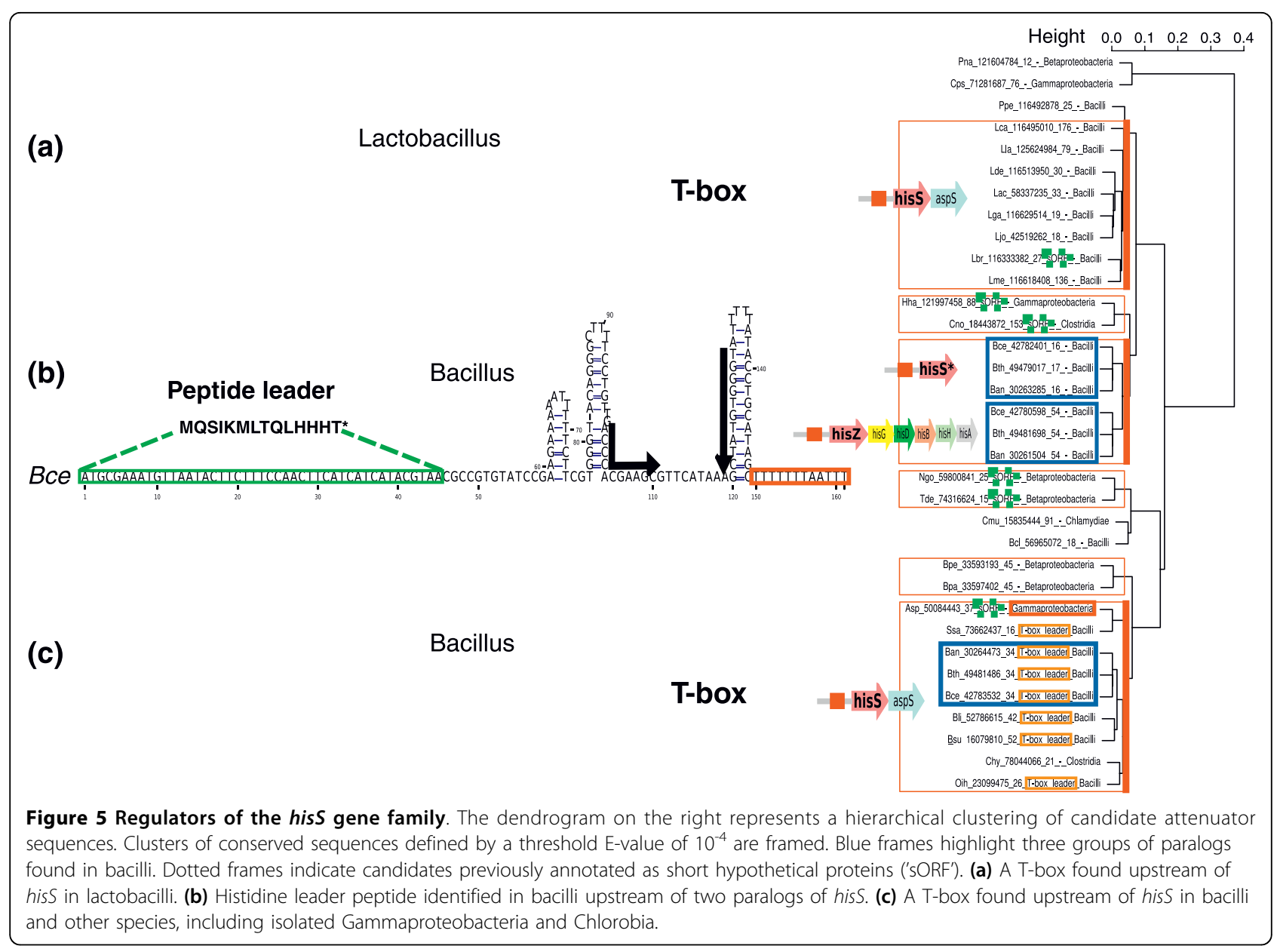

argues for a second mechanism in trans. Potrykus et al. [4] showed that overexpression of the short form of the greA transcript, released after attenuation has occurred, leads to repression of several genes. Furthermore, an intergenic region corresponding to the $r n k$-leader was found in a systematic screening [56] to co-immunoprecipitate with Hfq, a conserved bacterial protein known to facilitate interaction between small RNAs and their target mRNA. Although leaders doubling as trans-acting RNAs is a recent and, for the time being, rare finding [57], we may have found here two such cases with the greA- and $r n k$-leader families.

\section{Identification of attenuator 'regulons'}

The term 'regulon' or 'modulon' [58] has been coined to describe a set of genes subject to a common regulatory element. We analyzed attenuator regulons involving members of one or more gene families. To this intent, we compared sequences surrounding predicted 5 ' terminators across all genes with no consideration for orthology in a set of related species. We then clustered similar 5 ' sequences based on pairwise distances in so-called 'terminator clusters'. We describe here results obtained in the Enterobacteria (13 species) and Bacillus (8 species) subfamilies. Surveyed species are listed in Table S6 in Additional file 1. We identified a total of 192 and 270 terminator clusters in Enterobacteria and bacilli, respectively. We distinguished clusters based on the nature of downstream genes. Clusters involving only orthologous genes overlap the previous analysis and are given in Tables S4 and S5 in Additional file 1. We focus below on clusters involving several non-orthologous genes or groups of genes present in a single or a few related species.

\section{'Mobile attenuators' associated with transposable elements}

Forty-six terminator clusters in Enterobacteria and 96 clusters in bacilli are associated with transposable elements. We describe them as 'mobile attenuators'. Terminator sequences in these clusters show a high level of conservation, consistent with an origin from transposable elements of recent dissemination. They fall into two classes. The first class (Figure 7a) corresponds to terminators located upstream of transposases or other insertion sequence (IS)-related genes and is mainly 


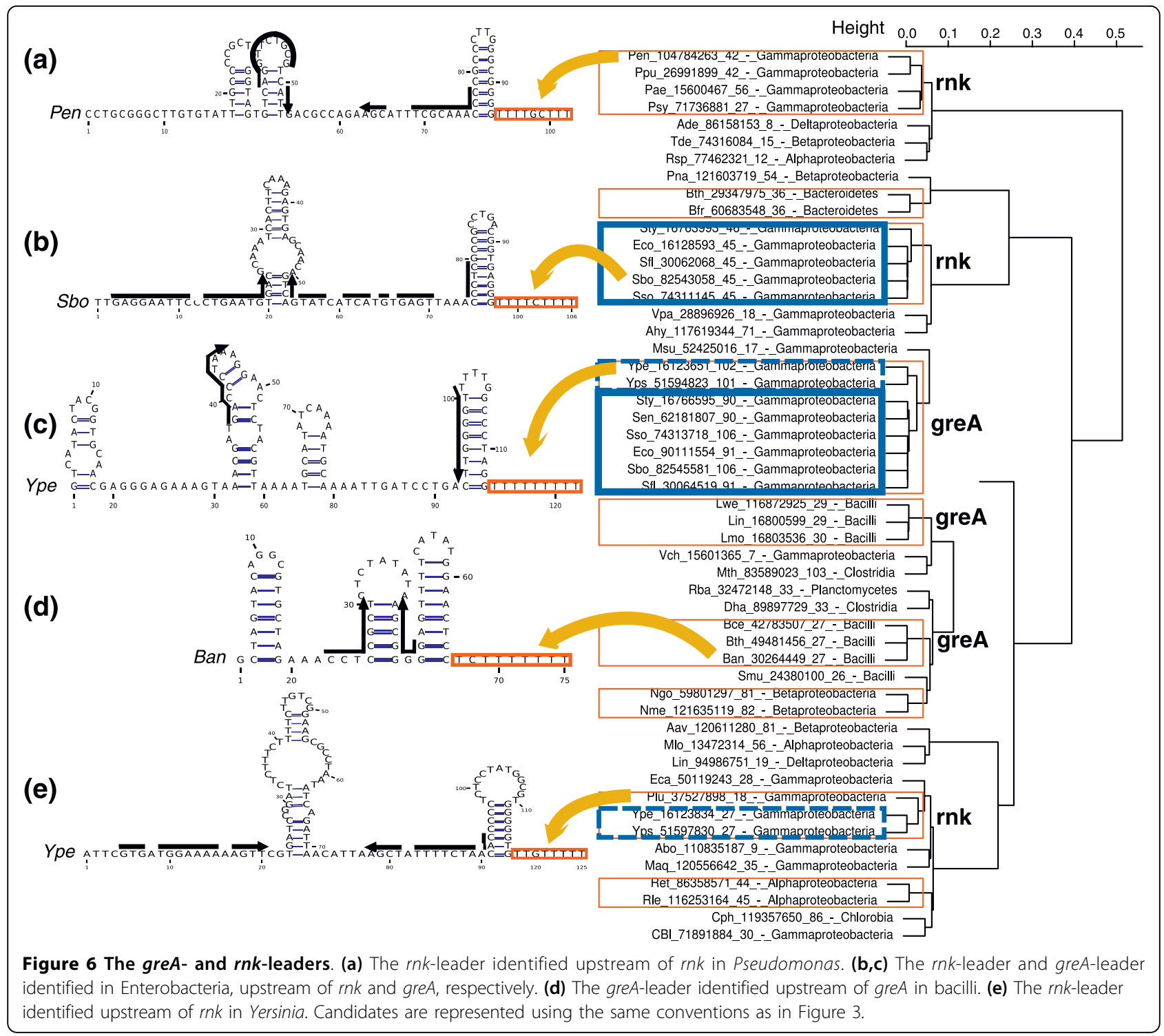

species-specific. Of note, transposase or IS-related genes also rank high in the list of frequently attenuated gene families, when no normalization for family size is applied (Table S0 in Additional file 1). These genes belong to transposon families such as ISBma2 (mainly present in the Betaproteobacteria Burkholderia mallei, in Bacillus thuringiensis and in the Clostridia Symbiobacterium thermophilum, Thermoanaerobacter tengcongensis and Clostridium novyi), IS3/IS2/IS600/IS1329/ IS407 A (found sporadically in all phyla) and ISL3 (mainly present in different Firmicutes species). The second class of mobile attenuators (Figure $7 \mathrm{~b}$ ) represents families of related transposon-borne sequences located immediately upstream of different, unrelated cellular genes.
The emergence of mobile attenuators can be explained by the structure of the IS containing both 3' and 5' transcription terminators [59,60] (Figure 7). Terminators of the first class correspond to IS 5' terminators, whose function is to limit transposon proliferation when inserted in a coding region under control of an active promoter. Such transposition events would be deleterious for the host, and consequently for the element's own survival. Clusters of conserved attenuators located upstream of unrelated genes (Figure $7 \mathrm{~b}$ ) may correspond to 3' terminators of ISs. The significant proportion (25 to $35 \%$ ) of conserved terminator clusters that result from IS transposition suggests they have a significant impact in genome evolution, particularly in terms of regulation. The possible pseudogenization of transposed 


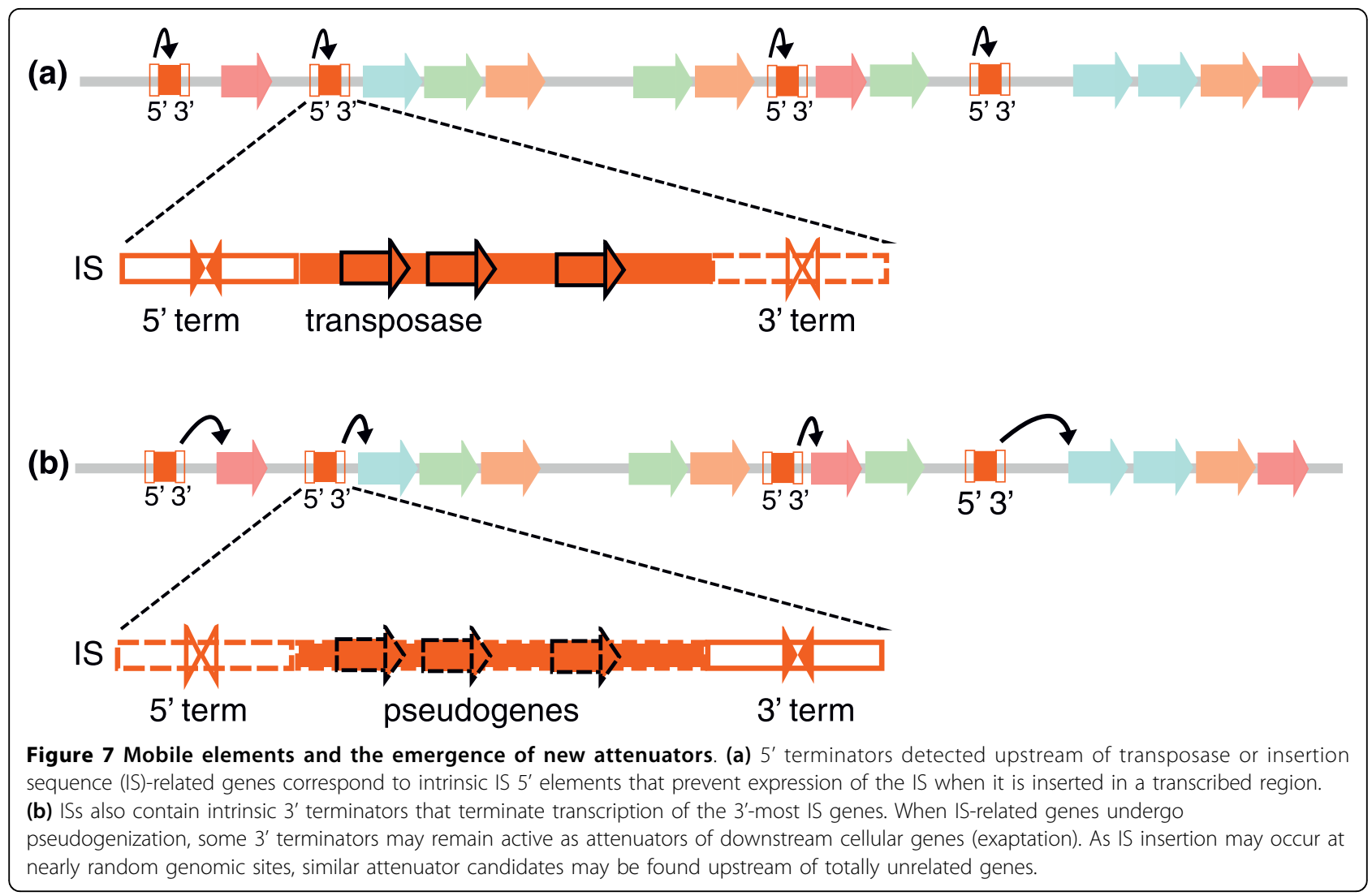

genes may allow exaptation of their 5' and/or 3' terminators and give birth to new regulatory elements (Figure $7 \mathrm{~b}$ ). It should be noted that this exaptation of transposable elements for regulatory functions is probably a universal mechanism, as several instances are already described in eukaryotic genomes [61,62].

\section{Non-insertion sequence related regulons}

Ten terminator clusters in Enterobacteria and 23 in bacilli are found in different species associated with the same set of non-homologous genes. They may therefore constitute attenuator regulons (Tables S4 and S5 in Additional file 1). Several known riboswitches fall in this class (15 out of 23 clusters in bacilli), which is consistent with the ability of riboswitches to occur upstream of unrelated genes from distant species. Analysis of these clusters thus seems promising for the identification of new regulons, although this class also contains sequences from repeated elements. For instance, the largest cluster detected in Enterobacteria (Figure 8) involves elements conserved upstream of the $\operatorname{gat} Y, \operatorname{rbf} A$, $c v p A$ and, in some cases, $m s c S, d p p B, y i d B$ and $s b p$ genes. Several members of this cluster present significant similarities with the rtT transcript identified by Bösl and Kersten [63], a by-product of the tyr $T$ operon that could have a role in stringent response, supporting the biological significance of these candidate attenuators.
Interestingly, we found these highly conserved elements to belong to bacterial interspersed mosaic elements (BIMEs) [64]. Even though this is a repeated element, it probably constitutes a bona fide attenuator as well. Indeed, BIMEs have been shown to act as bidirectional transcription terminators [65] and to induce transcriptional attenuation when placed upstream of a tRNA reporter gene [66]. The high conservation of these repeats, both in sequence and physical location, among Enterobacteria supports an exaptation scenario, possibly as an attenuator system. A second large attenuator cluster involving the genes $a r t J, y g d L, y h f Z$ and $y i j O$ was also found to correspond to BIMEs (Table S4 in Additional file 1).

Clusters of attenuators located upstream of different genes suggest coexpression, and therefore functional relationships between these genes. In bacilli, an interesting such element, which we called the 'vanR-leader', was found upstream of a gene encoding a flavin oxidoreductase and of the $v a n R$ gene, encoding a TCS transcription factor involved in vanillate catabolism (Figure 9; alignment in Supplementary data 3 in Additional file 1), suggesting a concerted regulation of these two genes. Another common element is found upstream of a sulfonate $\mathrm{ABC}$ transporter operon and upstream of an unknown gene. Its involvement in sulfonate metabolism 


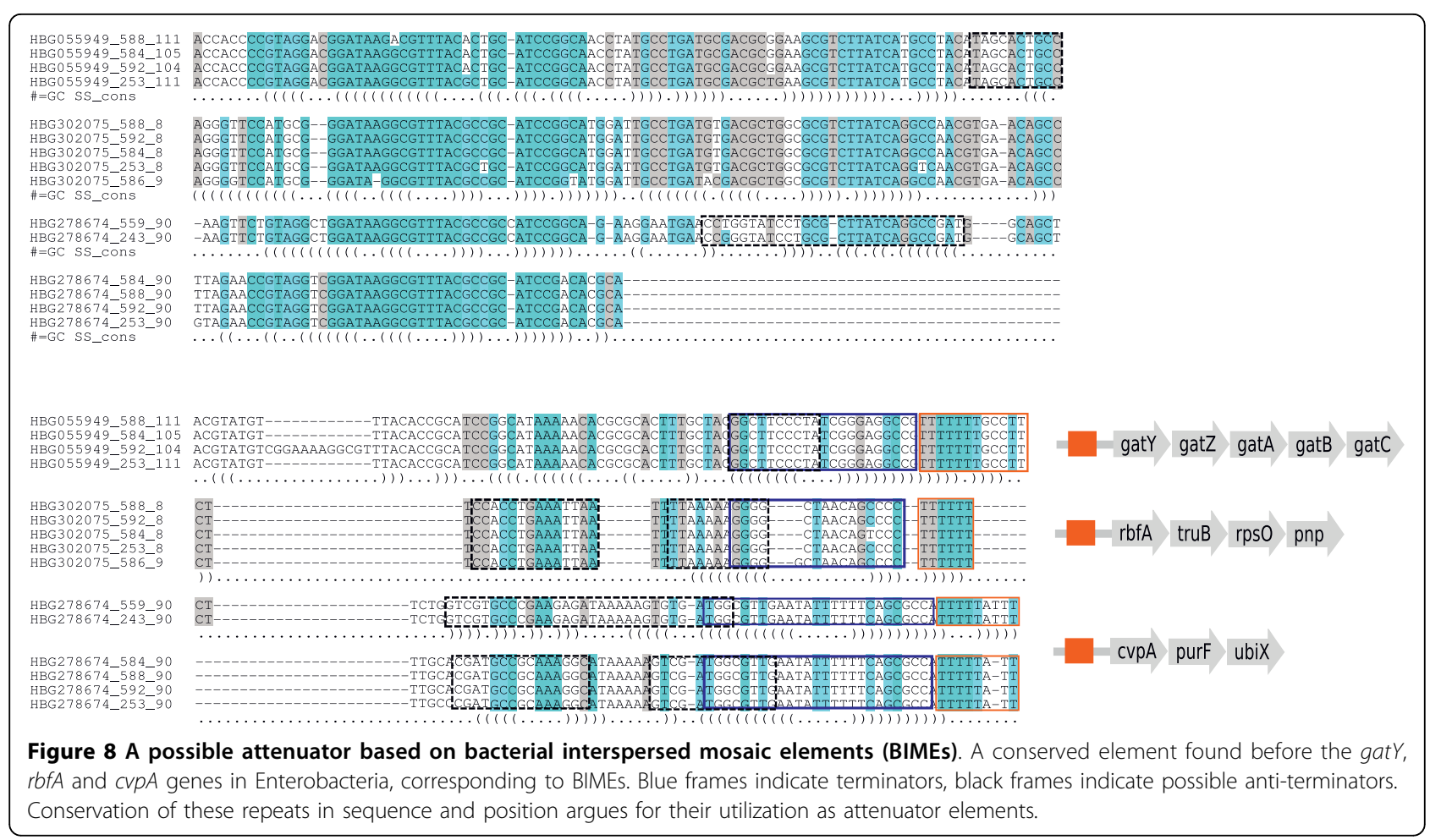

may consequently be hypothesized (alignment in Supplementary data 3 in Additional file 1). Finally, a cluster of related attenuators, which we named ' $f a b H$-leaders', involves elements upstream of the $f a b H$ gene, involved in fatty acid metabolism, and upstream of genes encoding a DNA binding protein, for which an association with the same pathway would be interesting to test (alignment in Supplementary data 3 in Additional file 1).

\section{Conclusions}

Broad-spectrum detection techniques are required to capture a larger fraction of attenuator diversity

In this study we apply a detection protocol that is able to capture a large spectrum of 5' regulatory sequences. Analysis of associated genes allowed us to list genes most frequently controlled by attenuation, and to further describe their attenuators. While previous computational screens based on sequence/structure homology were successful at identifying many distinct elements such as T-boxes or riboswitches [9,10,19-21], they tend to suggest a discrete occurrence of specific elements, while the reality looks more as a continuous landscape of evolving elements that explore all possible sensing systems offered by 5' UTR regulation. An illustration of this diversity is provided by the extensive analysis released by Weinberg et al. [67], who screened all available bacterial genomes for structured RNA and unearthed more than a hundred new significant motifs, most of which are probable cis-regulators. Strikingly, none of these motifs overlaps our major attenuator

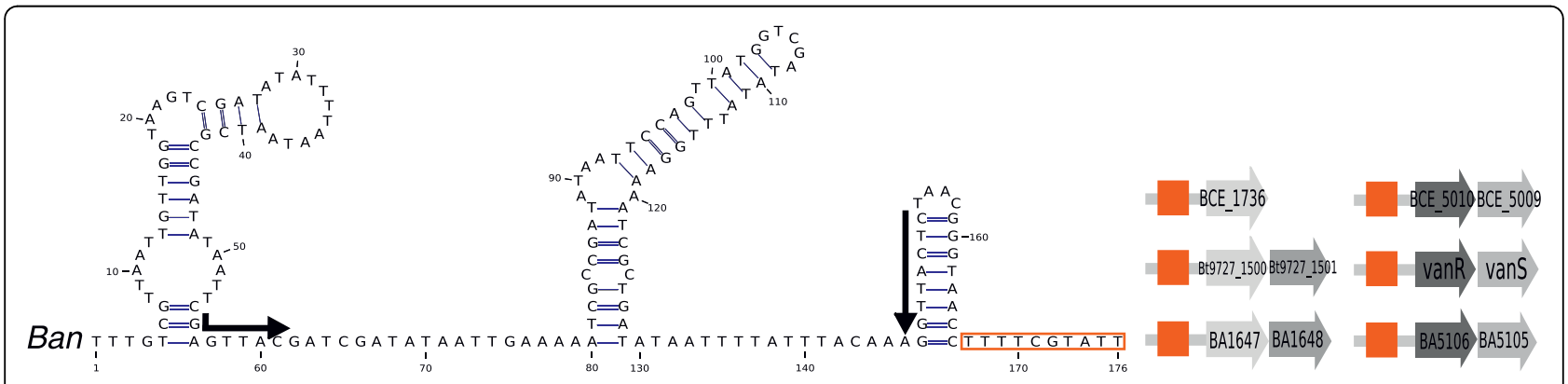

Figure 9 The $\boldsymbol{v a n R}$-leader. This element is conserved in bacilli, upstream of genes encoding a flavin oxidoreductase and a TCS DNA binding element (VanR). Candidates are represented using the same conventions as in Figure 3. 
families in Figure 1. Indeed, many of the sensing systems used by attenuators do not involve an RNA structure or evolve too rapidly to be caught by conservation analysis. Here we captured them using a simple terminator motif that, although it is not present in all cisregulatory RNAs (some use translational control or cryptic terminators), was able to detect a variety of elements not represented in current databases or literature.

An obvious limitation of our protocol is that it misses cases of Rho-dependent termination. However, only one instance of a Rho-dependent terminator-based attenuator has been described to date, in $E$. coli [68]. We can furthermore hypothesize that regulation more likely uses Rho-independent structures, which do not need any additional protein to function and thus may be more responsive to external challenges. Another limitation of computational attenuator detection is that it cannot unambiguously discriminate attenuators from independent non-coding RNAs when the later meet all search criteria (that is, if they are terminated by a Rhoindependent structure and located directly upstream of a gene in the same orientation). The main non-experimental clue to this question could lay in the synteny conservation between different strains: linkage of attenuator element and flanking gene strongly argues in favor of a cis-acting element. However, as some trans-acting small RNAs tend to retain their physical location for co-regulation reasons, no absolute rule can be drawn.

Our analysis should result in a better annotation of bacterial intergenic regions. It is likely, for instance, that many short ORFs currently annotated as hypothetical proteins and located upstream of operons, which we purposely considered as intergenic sequences, will turn out to be leader peptides or other attenuation systems. Indeed, among the top 30 families of Figure 1, 14 candidates from 8 different families were previously annotated as short hypothetical proteins, which was probably erroneous.

\section{A harvest of mobile terminators and clues for possible exaptative scenarios}

From an evolutionary viewpoint, it is interesting that unrelated organisms may use different sensing systems to regulate the same genes. We observed such interchanges in most of the families we studied. A recurrent scenario that was previously documented is the switch between a T-box in Firmicutes and a leader peptide in Proteobacteria $[9,10]$. One of our noticeable finding, however, is the presence of 'regular' leader peptides in Firmicutes, replacing T-boxes.

Interestingly, we noticed a tendency for RNA-binding protein genes to be more often regulated by attenuation than other genes: while about $5 \%$ of $B$. subtilis operons present a predicted attenuator, this proportion reaches
$14 \%$ among operons encoding at least one RNA-binding protein (data not shown). As several RNA-binding proteins are now shown to regulate their own expression at the transcriptional level (for example, ribosomal proteins [11], PyrR [12] or E. coli threonyl-tRNA synthetase [69]), it is tempting to postulate that many other RNA-binding proteins may harbor such dual-functionality, as illustrated in Figure 10a. In the same way, DNA-binding factors tend to regulate their own expression at the DNA- level (Figure 10b) [70,71]. It is tempting to consider possible evolutionary shifts between these two models. A number of attenuator elements identified in this study were previously assigned to palindromes interacting with transcription factors at the DNA level (MarR- or LysR-binding sites for instance). The switch from one system to another is conceivable with the emergence of a second transcription start site upstream or downstream of the palindrome sequence. Such tandem transcription start sites are quite frequent $[72,73]$ and may give rise to bifunctional elements acting both as terminator and transcription factor binding sites (Figure 10) and possibly interacting with two different protein partners. It would be interesting to test such a hypothesis. Other potentially bifunctional terminators would involve sequestration of a RBS by the terminator hairpin, inducing a concerted transcriptional and translational attenuation. While no such case has been experimentally demonstrated to date, it is noticeable that 18 candidate attenuators in $E$. coli are located under 15 nucleotides from the start codon, three of which are annotated as RBS-sequestrator in the RegulonDB database [39]. A switch from one system to the other is therefore a realistic hypothesis.

\section{Materials and methods}

Identification of putative elements involving a Rhoindependent terminator

Genome sequences and ORF annotations were retrieved from the National Center for Biotechnology Information (NCBI) database. The list of analyzed species and corresponding GenBank IDs is presented in Table S7 in Additional file 1 . In a first stage, we looked for Rho-independent terminators in intergenic regions, as well as in regions encompassing short ORFs ( $<200$ nucleotides) encoding hypothetical proteins as well as leader peptides (considered as a particular case of transcriptional attenuation), so as to potentially reannotate some of them. A terminator search was carried out using a combination of ERPIN [32] and RNAMOTIF [33]. ERPIN is a profile detection algorithm that takes as input a structure-annotated alignment. Here we used a training set of 1,200 terminator sequences from B. subtilis and E. coli. For the RNAMOTIF search, we used the descriptor of Lesnik et al. [74]. This descriptor consists essentially of a 4- to 


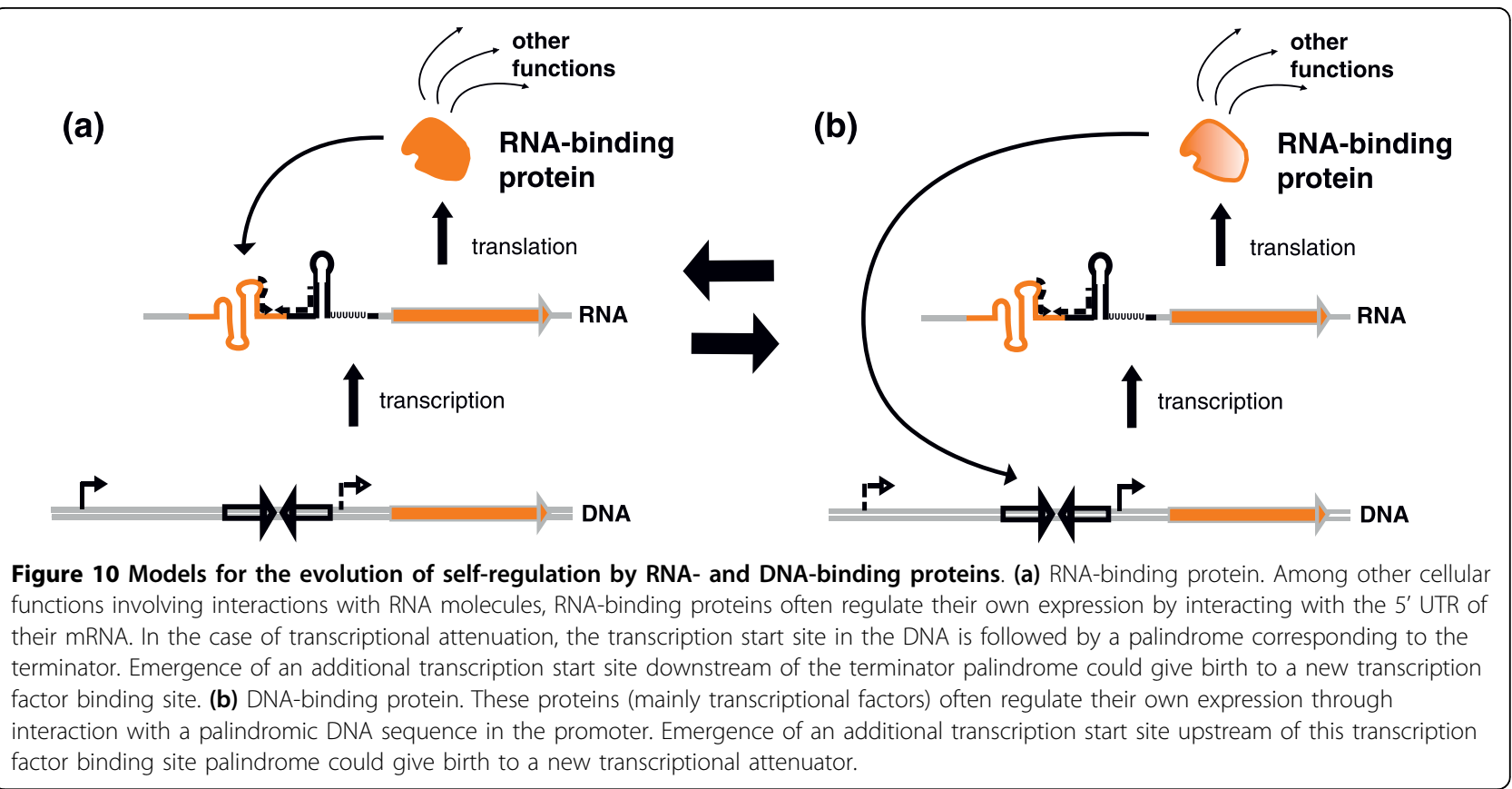

18-bp helix, a 0 - to 2-nucleotide spacer and a 12 nucleotide T-rich region. Parameters and input files for each program are given in Supplementary data 4 in Additional file 1. In this study, terminators were first sought using ERPIN, and in a second stage using RNAMOTIF when ERPIN was not able to detect any motif. In tests conducted with randomized terminator sequences, the combination of these two programs produced, on average, 47 false positive hits per 1,000 intergenic regions of size 115 nucleotides [35]. In this study, we further compared the specificity of terminator detections in 5' and 3' UTR sequences by generating, for each predicted terminator, two sets of 100 randomized sequences of the same dinucleotide composition as 5' and 3' UTRs, respectively, and applying our prediction protocol to each set.

To be considered as candidate attenuators, terminators had to be in the same orientation as the downstream gene and at a suitable distance to avoid incorporation of canonical 3' terminators (from the upstream gene or from an undetected non-coding RNA present in the intergenic region). To this effect, terminators located at a distance ratio (that is, the ratio of the distance from the downstream gene to the distance from the upstream gene) greater than 1:1 or further than 300 nucleotides from the first codon of the downstream gene were discarded. Final predictions are listed in Table S8 in Additional file 1.

\section{Annotation of attenuator candidates and genes}

Attenuator candidates were defined as the sequences from the limit of the upstream gene - or a maximum of
200 nucleotides - to the position immediately 3' of the terminator. Candidates were assigned to Rfam 10.0 [38] families by similarity search using Blast [75] with the following parameters: -p blastn, -G 2, -E 1, -W 7, -e 0.0001. Hits were retained if the match covered more than $50 \%$ of the full length of the Rfam entry. Candidates that failed to match a Rfam family with Blast were further submitted to covariance search using the rfam_scan.pl script provided on the Rfam web site [38]. Attenuator candidates that could not be annotated using these methods were submitted to a literature search based on the function of the downstream gene, or searched in the RegulonDB [39] for $E$. coli candidates. We assigned functions to bacterial genes using BlastP against the Hogenom database [37] and retrieving the corresponding Hogenom IDs.

\section{Hogenom family scoring}

Each Hogenom family of homologous genes [37] was scored in two ways. The absolute score was defined as the absolute number of predicted attenuators upstream of all genes in the family across all 302 species (Table S0 in Additional file 1). The normalized score was computed as follows: for a given Hogenom family, the number of candidates in each species was normalized by the total number of genes in this species for this family. These single-species scores were then summed across all species. Lastly, in order to favor evolutionarily parsimonious distributions, we arranged single-species scores in a phylogenetic order and weighted consecutive non-zero scores by a factor of +0.1 times the length of the non-zero stretch. We confirmed the statistical significance of the 
enrichment of 5 terminators in each Hogenom family using Fisher's exact tests with the following values: number of genes in the Hogenom family; total number of genes assessed; number of genes with $5^{\prime}$ terminators in the Hogenom family; total number of genes with 5' terminators.

\section{Clustering of attenuator sequences}

For sequence analysis, we extracted regions around putative Rho-independent terminators, from the limit of the upstream gene (or a maximum of 200 nucleotides) to the position immediately 3 ' of the terminator. The distance between two sequences was defined as the inverse of the best hit score obtained by Blast/bl2seq [75]. We then performed hierarchical clustering from the distance matrix using the 'hclust' procedure from the $\mathrm{R}$ package [76]. Clusters were defined by pruning the tree at a height of 0.038 (corresponding to an E-value of approximately $10^{-4}$ ) determined empirically so as to cluster exclusively elements known to belong to the same family. For each cluster, we performed a multiple sequence alignment using ClustalW [77] followed by consensus structure prediction with the RNAalifold program [78].

RNA alignments and structures were refined and analyzed using the Ralee Emacs extension [79]. RNA structures were drawn using the Varna applet [80].

\section{Additional material}

Additional file 1: Supplementary tables and figures. Table SO: gene families showing the highest absolute numbers of attenuator candidates. Table S1: genes most frequently regulated by attenuation in bacteria (normalized by family size). Table S2: list of sequence clusters observed in the 30 gene families most often regulated by attenuation (tabulationseparated). Table S3: sequence clusters obtained among candidates upstream of ABC-transporter genes. Table S4: complete list of clusters obtained by analyzing all candidates from enterobacterial species listed in Table S6. Cluster classes: 'a', clusters including only orthologous genes. ' $b$ ', clusters including only non-orthologous genes, sometimes from a single species; 'c', 'super-clusters' containing several sets of orthologous genes. Table S5: complete list of clusters obtained by analyzing all the candidates of Bacillus species listed in Table S6. 'a', clusters including only orthologous genes; ' $b$ ', clusters including only non-orthologous genes, sometimes from a single species; 'c', 'super-clusters' containing several sets of orthologous genes. Table S6: list of species analyzed for the identification of attenuators 'regulons'. Table 57: complete list of analyzed species, along with GenBank identifiers of corresponding DNA molecules and clade. Table S8: complete list of attenuators predicted in 5' UTR of genes, using the protocol described in [31] (tab-delimited table).

Supplementary data 1: list of rimP-leaders from Gammaproteobacteria; list of rimP-leaders from other species; list of intergenic regions where no terminator could be detected, but showing sequence similarity to putative attenuators. Supplementary data 2: Stockholm alignments of the five ABC-leaders shown in Figure 4. Supplementary data 3: lists and Stockholm alignments of attenuator 'regulons' (candidates present upstream of several non-homologous genes) in Firmicutes.

Supplementary data 4: parameters, commands and descriptor files used for terminator prediction.

\section{Abbreviations}

ABC: ATP-binding cassette; BIME: bacterial interspersed mosaic element; bp: base pair; IS: insertion sequence; ORF: open reading frame; RBS: ribosomebinding site; TCS: two-component system; UTR: untranslated region.

\section{Authors' contributions}

MN and DG both contributed to the experimental design, data analysis and writing of the manuscript. MN performed the experiments.

Received: 12 April 2010 Revised: 11 August 2010

Accepted: 29 September 2010 Published: 29 September 2010

\section{References}

1. Nagalakshmi U, Wang Z, Waern K, Shou C, Raha D, Gerstein M, Snyder M: The transcriptional landscape of the yeast genome defined by RNA sequencing. Science 2008, 320:1344-1349.

2. Taft RJ, Glazov EA, Cloonan N, Simons C, Stephen S, Faulkner GJ, Lassmann T, Forrest AR, Grimmond SM, Schroder K, Irvine K, Arakawa T, Nakamura M, Kubosaki A, Hayashida K, Kawazu C, Murata M, Nishiyori H, Fukuda S, Kawai J, Daub CO, Hume DA, Suzuki H, Orlando V, Carninci P, Hayashizaki Y, Mattick JS: Tiny RNAs associated with transcription start sites in animals. Nat Genet 2009, 41:572-578.

3. Jacquier $A$ : The complex eukaryotic transcriptome: unexpected pervasive transcription and novel small RNAs. Nat Rev Genet 2009, 10:833-844.

4. Potrykus K, Murphy H, Chen X, Epstein JA, Cashel M: Imprecise transcription termination within Escherichia coli greA leader gives rise to an array of short transcripts, GraL. Nucleic Acids Res 2010, 38:1636-1651.

5. Neil H, Malabat C, d'Aubenton-Carafa $Y, X u Z$ Z, Steinmetz LM, Jacquier A: Widespread bidirectional promoters are the major source of cryptic transcripts in yeast. Nature 2009, 457:1038-1042.

6. Coppins L, Hall KB, Groisman EA: The intricate world of riboswitches. Curr Opin Microbiol 2007, 10:176-181.

7. Henkin TM: Riboswitch RNAs: using RNA to sense cellular metabolism. Genes Dev 2008, 22:3383-3390.

8. Dambach MD, Winkler WC: Expanding roles for metabolite-sensing regulatory RNAs. Curr Opin Microbiol 2009, 12:161-169.

9. Vitreschak AG, Mironov AA, Lyubetsky VA, Gelfand MS: Comparative genomic analysis of T-box regulatory systems in bacteria. RNA 2008, 14:717-735.

10. Gutiérrez-Preciado A, Henkin TM, Grundy FJ, Yanofsky C, Merino E: Biochemical features and functional implications of the RNA-based Tbox regulatory mechanism. Microbiol Mol Biol Rev 2009, 73:36-61.

11. Nomura M, Yates JL, Dean D, Post LE: Feedback regulation of ribosomal protein gene expression in Escherichia coli: structural homology of ribosomal RNA and ribosomal protein mRNA. Proc Natl Acad Sci USA 1980, 77:7084-7088.

12. Bonner ER, D'Elia JN, Billips BK, Switzer RL: Molecular recognition of pyr mRNA by the Bacillus subtilis attenuation regulatory protein PyrR. Nucleic Acids Res 2001, 29:4851-4865.

13. Amster-Choder $\mathrm{O}$ : The bgl sensory system: a transmembrane signaling pathway controlling transcriptional antitermination. Curr Opin Microbiol 2005, 8:127-134.

14. Narberhaus F, Waldminghaus T, Chowdhury S: RNA thermometers. FEMS Microbiol Rev 2006, 30:3-16.

15. Waldminghaus T, Gaubig LC, Narberhaus F: Genomewide bioinformatics prediction and experimental évaluation of potential RNA thermometers. Mol Genet Genomics 2007, 278:555-564.

16. Chowdhury S, Maris C, Allain FH, Narberhaus F: Molecular basis for temperature sensing by an RNA thermometer. EMBO J 2006, 25:2487-2497.

17. Merino E, Yanofsky C: Transcription attenuation: a highly conserved regulatory strategy used by bacteria. Trends Genet 2005, 21:260-264.

18. Liubetskaia EV, Leont'ev LA, Gel'fand MS, Liubetskii VA: [Search for alternative RNA secondary structures regulating expression of bacterial genes]. Mol Biol (Mosk) 2003, 37:707-716.

19. Barrick JE, Corbino KA, Winkler WC, Nahvi A, Mandal M, Collins J, Lee M, Roth A, Sudarsan N, Jona I, Wickiser JK, Breaker RR: New RNA motifs suggest an expanded scope for riboswitches in bacterial genetic control. Proc Natl Acad Sci USA 2004, 101:6421-6426. 
20. Barrick JE, Breaker RR: The distributions, mechanisms, and structures of metabolite-binding riboswitches. Genome Biol 2007, 8:R239.

21. Yao Z, Barrick J, Weinberg Z, Neph S, Breaker R, Tompa M, Ruzzo WL: A computational pipeline for high-throughput discovery of cis-regulatory noncoding RNA in prokaryotes. PLoS Comput Biol 2007, 3:e126.

22. Vitreschak AG, Lyubetskaya EV, Shirshin MA, Gelfand MS, Lyubetsky VA: Attenuation regulation of amino acid biosynthetic operons in proteobacteria: comparative genomics analysis. FEMS Microbiol Lett 2004, 234:357-370.

23. Chang TH, Huang HD, Wu LC, Yeh CT, Liu BJ, Horng JT: Computational identification of riboswitches based on RNA conserved functional sequences and conformations. RNA 2009, 15:1426-1430.

24. Grundy FJ, Henkin TM: The $S$ box regulon: a new global transcription termination control system for methionine and cysteine biosynthesis genes in gram-positive bacteria. Mol Microbiol 1998, 30:737-749.

25. Epshtein V, Mironov AS, Nudler E: The riboswitch-mediated control of sulfur metabolism in bacteria. Proc Natl Acad Sci USA 2003, 100:5052-5056.

26. Winkler WC, Nahvi A, Sudarsan N, Barrick JE, Breaker RR: An mRNA structure that controls gene expression by binding $\mathrm{S}$ adenosylmethionine. Nat Struct Biol 2003, 10:701-707.

27. Corbino KA, Barrick JE, Lim J, Welz R, Tucker BJ, Puskarz I, Mandal M, Rudnick ND, Breaker RR: Evidence for a second class of Sadenosylmethionine riboswitches and other regulatory RNA motifs in alpha-proteobacteria. Genome Biol 2005, 6:R70.

28. Fuchs RT, Grundy FJ, Henkin TM: The SMK box is a new SAM-binding RNA for translational regulation of SAM synthetase. Nat Struct Mol Biol 2006, 13:226-233.

29. Weinberg Z, Regulski EE, Hammond MC, Barrick JE, Yao Z, Ruzzo WL, Breaker RR: The aptamer core of SAM-IV riboswitches mimics the ligandbinding site of SAM-I riboswitches. RNA 2008, 14:822.

30. Poiata E, Meyer MM, Ames TD, Breaker RR: A variant riboswitch aptamer class for S-adenosylmethionine common in marine bacteria. RNA 2009, 15:2046-2056.

31. Naville $M$, Gautheret $D$ : Transcription attenuation in bacteria: theme and variations. Brief Funct Genomic Proteomic 2009, 8:482-492.

32. Gautheret D, Lambert A: Direct RNA motif definition and identification from multiple sequence alignments using secondary structure profiles. J Mol Biol 2001, 313:1003-1011.

33. Macke TJ, Ecker DJ, Gutell RR, Gautheret D, Case DA, Sampath R: RNAmotif, an RNA secondary structure definition and search algorithm. Nucleic Acids Res 2001, 29:4724-4735.

34. de Hoon MJ, Makita Y, Nakai K, Miyano S: Prediction of transcriptional terminators in Bacillus subtilis and related species. PLoS Comput Biol 2005, 1:e25.

35. Naville M, Ghuillot-Gaudeffroy A, Gautheret D: ARNold: a web tool for the prediction of Rho-independent transcription terminators. RNA Biol 2011.

36. Marchais A, Naville M, Bohn C, Bouloc P, Gautheret D: Single-pass classification of all noncoding sequences in a bacterial genome using phylogenetic profiles. Genome Res 2009, 19:1084-1092.

37. Dufayard JF, Duret L, Penel S, Gouy M, Rechenmann F, Perrière G: Tree pattern matching in phylogenetic trees: automatic search for orthologs or paralogs in homologous gene sequence databases. Bioinformatics 2005, 21:2596-2603.

38. Gardner PP, Daub J, Tate JG, Nawrocki EP, Kolbe DL, Lindgreen S, Wilkinson AC, Finn Rd, Griffiths-Jones S, Eddy SR, Bateman A: Rfam: updates to the RNA families database. Nucleic Acids Res 2009, 37: D136-140.

39. Gama-Castro S, Jimenez-Jacinto V, Peralta-Gil M, Santos-Zavaleta A, Peñaloza-Spindola MI, Contreras-Moreira B, Segura-Salazar J, MuñizRascado L, Martinez-Flores I, Salgado H, Bonavides-Martinez C, AbreuGoodger C, Rodriguez-Penagos C, Miranda-Rios J, Morett E, Merino E, Huerta AM, Trevino-Quintanilla L, Collado-Vides J: RegulonDB (version 6.0): gene regulation model of Escherichia coli K-12 beyond transcription, active (experimental) annotated promoters and Textpresso navigation. Nucleic Acids Res 2008, , 36 Database: D120-124.

40. Nord S, Bylund GO, Lövgren JM, Wikström PM: The RimP protein is important for maturation of the $30 \mathrm{~S}$ ribosomal subunit. J Mol Biol 2009, 386:742-753.

41. Beuth B, Pennell S, Arnvig KB, Martin SR, Taylor IA: Structure of a Mycobacterium tuberculosis NusA-RNA complex. EMBO J 2005, 24:3576-3587.
42. Plumbridge JA, Dondon J, Nakamura Y, Grunberg-Manago M: Effect of NusA protein on expression of the nusA,infB operon in E. coli. Nucleic Acids Res 1985, 13:3371-3388.

43. Nakamura Y, Plumbridge J, Dondon J, Grunberg-Manago M: Evidence for autoregulation of the nusA-infB operon of Escherichia coli. Gene 1985, 36:189-193,

44. Shibata R, Bessho Y, Shinkai A, Nishimoto M, Fusatomi E, Terada T, Shirouzu M, Yokoyama S: Crystal structure and RNA-binding analysis of the archaeal transcription factor NusA. Biochem Biophys Res Commun 2007, 355:122-128

45. Worbs M, Bourenkov GP, Bartunik HD, Huber R, Wahl MC: An extended RNA binding surface through arrayed $\mathrm{S} 1$ and $\mathrm{KH}$ domains in transcription factor NusA. Mol Cell 2001, 7:1177-1189.

46. Irnov I, Sharma CM, Vogel J, Winkler WC: Identification of regulatory RNAs in Bacillus subtilis. Nucleic Acids Res 2010.

47. Saito K, Mattheakis LC, Nomura M: Post-transcriptional regulation of the str operon in Escherichia coli: Ribosomal protein S7 inhibits coupled translation of S7 but not its independent translation. J Mol Biol 1994, 235:111-124.

48. Meyer MM, Ames TD, Smith DP, Weinberg Z, Schwalbach MS, Giovannoni SJ, Breaker RR: Identification of candidate structured RNAs in the marine organism 'Candidatus Pelagibacter ubique'. BMC Genomics 2009, 10:268.

49. Robert F, Gagnon M, Sans D, Michnick S, Brakier-Gingras L: Mapping of the RNA recognition site of Escherichia coli ribosomal protein S7. RNA 2000, 6:1649-1659

50. Davidson AL, Dassa E, Orelle C, Chen J: Structure, function, and evolution of bacterial ATP-binding cassette systems. Microbiol Mol Biol Rev 2008, 72:317-364.

51. Moussatova A, Kandt C, O'Mara ML, Tieleman DP: ATP-binding cassette transporters in Escherichia coli.. Biochim Biophys Acta 2008, 1778:1757-1771.

52. Grkovic S, Brown MH, Skurray RA: Regulation of bacterial drug export systems. Microbiol Mol Biol Rev 2002, 66:671-701.

53. Ohki R, Tateno K, Takizawa T, Aiso T, Murata M: Transcriptional termination control of a novel $A B C$ transporter gene involved in antibiotic resistance in Bacillus subtilis. J Bacteriol 2005, 187:5946-5954.

54. Seliverstov AV, Putzer $\mathrm{H}$, Gelfand MS, Lyubetsky VA: Comparative analysis of RNA regulatory elements of amino acid metabolism genes in Actinobacteria. BMC Microbiol 2005, 5:54.

55. Gryczan TJ, Grandi G, Hahn J, Grandi R, Dubnau D: Conformational alteration of mRNA structure and the posttranscriptional regulation of erythromycin-induced drug resistance. Nucleic Acids Res 1980, 8:6081-6097.

56. Zhang A, Wassarman KM, Rosenow C, Tjaden BC, Storz G, Gottesman S: Global analysis of small RNA and mRNA targets of Hfq. Mol Microbiol 2003, 50:1111-1124.

57. Loh E, Dussurget O, Gripenland J, Vaitkevicius K, Tiensuu T, Mandin P, Repoila F, Buchrieser C, Cossart P, Johansson J: A trans-acting riboswitch controls expression of the virulence regulator PrfA in Listeria monocytogenes. Cell 2009, 139:770-779.

58. Rodionov DA: Comparative genomic reconstruction of transcriptional regulatory networks in bacteria. Chem Rev 2007, 107:3467-3497.

59. Davis MA, Simons RW, Kleckner N: Tn10 protects itself at two levels from fortuitous activation by external promoters. Cell 1985, 43:379-387.

60. Beuzon CR, Marques S, Casadesus J: Repression of IS200 transposase synthesis by RNA secondary structures. Nucleic Acids Res 1999, 27:3690-3695.

61. Bejerano G, Lowe CB, Ahituv N, King B, Siepel A, Salama SR, Rubin EM, Kent WJ, Haussler D: A distal enhancer and an ultraconserved exon are derived from a novel retroposon. Nature 2006, 441:87-90.

62. Lowe CB, Bejerano G, Haussler D: Thousands of human mobile element fragments undergo strong purifying selection near developmental genes. Proc Natl Acad Sci USA 2007, 104:8005-8010.

63. Bösl M, Kersten H: A novel RNA product of the tyrT operon of Escherichia coli. Nucleic Acids Res 1991, 19:5863-5870.

64. Gilson E, Saurin W, Perrin D, Bachellier S, Hofnung M: The BIME family of bacterial highly repetitive sequences. Res Microbiol 1991, 142:217-222.

65. Gilson E, Rousset JP, Clément JM, Hofnung M: A subfamily of E. coli palindromic units implicated in transcription termination? Ann Inst Pasteur Microbiol 1986, 137B:259-270. 
66. Espéli O, Moulin L, Boccard F: Transcription attenuation associated with bacterial repetitive extragenic BIME elements. J Mol Biol 2001, 314:375-386

67. Weinberg Z, Wang JX, Bogue J, Yang J, Corbino K, Moy RH, Breaker RR: Comparative genomics reveals 104 candidate structured RNAs from bacteria, archaea and their metagenomes. Genome Biol 2010, 11:R31.

68. Konan KV, Yanofsky C: Rho-dependent transcription termination in the tna operon of Escherichia coli: Roles of the boxA sequence and the rut site. J Bacteriol 2000, 182:3981-3988.

69. Romby P, Springer M: Bacterial translational control at atomic resolution. Trends Genet 2003, 19:155-161.

70. Schell MA: Molecular biology of the LysR family of transcriptional regulators. Annu Rev Microbiol 1993, 47:597-626.

71. Martin RG, Rosner JL: Transcriptional and translational regulation of the marRAB multiple anibiotic resistance operon in Escherichia coli. Mol Microbiol 2004, 53:183-191.

72. Toledo-Arana A, Dussurget O, Nikitas G, Sesto N, Guet-Revillet H, Balestrino D, Loh E, Gripenland J, Tiensuu T, Vaitkevicius K, Barthelemy M, Vergassola M, Nahori MA, Soubigou G, Régnault B, Coppée JY, Lecuit M, Johansson J, Cossart P: The Listeria transcriptional landscape from saprophytism to virulence. Nature 2009, 459:950-956.

73. Mendoza-Vargas A, Olvera L, Olvera M, Grande R, Vega-Alvarado L, Taboada B, Jimenez-Jacinto V, Salgado H, Juárez K, Contreras-Moreira B, Huerta AM, Collado-Vides J, Morett E: Genome-wide identification of transcription start sites, promoters and transcription factor binding sites in E. coli.. PLoS One 2009, 4:e7526.

74. Lesnik EA, Sampath R, Levene HB, Henderson TJ, McNeil JA, Ecker DJ: Prediction of Rho-independent transcriptional terminators in Escherichia coli. Nucleic Acids Res 2001, 29:3583-3594.

75. Altschul SF, Gish W, Miller W, Myers EW, Lipman DJ: Basic local alignment search tool. J Mol Biol 1990, 215:403-410.

76. R Development Core Team: R: A Language and Environment for Statistical Computing. 2009 [http://www.R-project.org].

77. Larkin MA, Blackshields G, Brown NP, Chenna R, McGettigan PA McWilliam H, Valentin F, Wallace IM, Wilm A, Lopez R, Thompson JD, Gibson TJ, Higgins DG: ClustalW and ClustalX version 2. Bioinformatics 2007, 23:2947-2948.

78. Bernhart SH, Hofacker IL, Will S, Gruber AR, Stadler PF: RNAalifold: improved consensus structure prediction for RNA alignments. BMC Bioinformatics 2008, 9:474.

79. Griffiths-Jones S: RALEE - RNA ALignment editor in Emacs. Bioinformatics 2005, 21:257-259.

80. Darty K, Denise A, Ponty Y: VARNA: Interactive drawing and editing of the RNA secondary structure. Bioinformatics 2009, 25:1974-1975.

81. Crooks GE, Hon G, Chandonia JM, Brenner SE: WebLogo: A sequence logo generator. Genome Res 2004, 14:1188-1190.

doi:10.1186/gb-2010-11-9-r97

Cite this article as: Naville and Gautheret: Premature terminator analysis sheds light on a hidden world of bacterial transcriptional attenuation.

Genome Biology 2010 11:R97.

\section{Submit your next manuscript to BioMed Central and take full advantage of:}

- Convenient online submission

- Thorough peer review

- No space constraints or color figure charges

- Immediate publication on acceptance

- Inclusion in PubMed, CAS, Scopus and Google Scholar

- Research which is freely available for redistribution

Submit your manuscript at www.biomedcentral.com/submit
Biomed Central 